\title{
Olhares sobre a tradição
}

\section{Observing tradition}

\author{
Lúcia Helena de Oliveira CUNHA*
}

\begin{abstract}
RESUMO
Este artigo reflete a respeito dos diferentes olhares que a modernidade projeta sobre as "sociedades da tradição", vendo-as ora do ponto de vista negativo, em suas desordens, ora do ponto de vista positivo, a partir de suas ordens imanentes. Pierre Clastres é um dos antropólogos contemporâneos que focaliza o modo através do qual as sociedades ditas primitivas são freqüentemente percebidas pela ausência, no prisma da civilização ocidental: pela falta de trabalho, de Estado e de ordem. George Balandier coloca em questão esse imaginário ocidental sobre as sociedades tradicionais, mesmo quando tais sociedades aparecem como expressão do positivo, do equilíbrio. Entendendo que ordem e desordem são categorias reguladoras da vida humana, para o autor, é preciso repensar o conceito de tradição dotado de movimento. Assim, os povos da tradição não podem ser vistos como estagnados, parados no tempo, mas imersos em outros ritmos temporais, mesmo no encontro (confronto) com a modernidade.
\end{abstract}

Palavras-chave: tradição, modernidade, movimento

\begin{abstract}
This article pretend procedure to the reflection of different view that the modernity project over "societies of tradition", look at them sometimes from the negative point of view in its disorder, sometimes from the positive point of view, from its order immanent. Pierre Clastres is one of our present anthropologist that focus the manner through the societies supposed primitive are often perceive by absence in the prism of occidental civilization: because of absence of job, state and order. George Balandier puts in question this occidental imaginary about traditional societies, even when those societies appears like expression of positive and of the balance. For Balandier order and disorder are regulator category of human life; this author thinks that we need rethink the conceit of tradition endowed of movement. Thus, "the people of tradition", can not be viewed like stagnated, standing up still, but immersed in others temporary rhythm, with own dynamics, even in the meeting (confront) with the modernity.
\end{abstract}

Key-words: tradition, modernity, movement

* Antropóloga, Mestre em Ciências Sociais - PUC-SP, professora aposentada da Universidade Federal da Paraíba-UFPB e colaboradora do NUPAUB - USP. 
Como num relampejar, imagina-se que a modernidade ingressa na ponta da história, deixando para trás todo o resto, como se uma ventania varresse o tempo, tornando o que passou coisa antiga, velha, esmaecida - ultrapassada.

E tudo de repente se altera num ritmo veloz: a natureza passa a ser segunda, em substituição à primeira, pela conquista e domínio dos homens; o desenvolvimento das técnicas e da ciência toma um impulso nunca antes visto; os espaços se ampliam e se intercruzam, encurtando as distâncias; os ritmos de tempo numa pulsação frenética produzem a aceleração da história. E tudo parece caminhar numa velocidade cada vez maior, em direção ao cada vez mais, num fluxo incomensurável - sem fim -, onde ser moderno é finalmente poder alcançar a história, adentrandose na "máquina do tempo". E tudo passa, deixando tudo para trás... Será?

Debruçar-se sobre o sentido da linha do tempo, tecida no imaginário moderno, em suas distintas vertentes, constitui sem dúvida um desafio para o repensar das possibilidades da humanidade nos limiares do contemporâneo; já há alguns séculos o homem - talvez cativo do seu "cogito" - sempre pensou estar caminhando numa marcha triunfal em direção ao progresso. Nessa marcha negadora do passado, marcada pelo antes e depois, as tradições (algumas tradições) parecem não ter lugar nem vez na história, a não ser como reminiscência ou como algo perdido nos resíduos do tempo.

Do ângulo da razão evolucionária que perpassa o pensamento social moderno, "tradição e modernidade" são vistas numa perspectiva linear, como estados ou momentos sucessivos do processo histórico, como se a modernidade se traduzisse necessariamente em avanço - estádio superior da vida humana. Em contrapartida, as chamadas formas tradicionais de produção são concebidas como atrasadas, estacionárias, pertencentes a uma fase evolutiva superada historicamente pelos "avanços" da modernidade.

Nessa linha de pensamento, tais economias são destituídas de racionalidade e dinâmica próprias e percebidas sempre pela negação - por tudo que lhes falta de "avançado" e de "moderno" na civilização industrial.

Deriva daí a imagem de que índios vivem em sociedades perdidas no tempo - no limite da sobrevivência -, com um grau de pobreza absoluta decorrente de sua incapacidade para o trabalho e de sua incompetência técnica em explorar os recursos naturais. São, inclusive, na visão da teoria econômica convencional, tidos como pertencentes a "sociedades de escassez" em oposição à dinâmica capitalista industrial considerada como "sociedade de abundância" (SAHLINS, 1978).

Com base em tal categorização, oriunda de imagens fantasmagóricas produzidas pela lógica mercantil, é que as sociedades da tradição são, pois, percebidas: "meras economias de subsistência, com lazer limitado, na busca incessante de comida, com recursos naturais pobres e relativamente incertos, com ausência de excedente econômico e utilizando o máximo de energia de um máximo de pessoas."

Contrariando esse tipo de visão, com todas as significações imaginárias que encerra, Sahlins busca inverter as proposições ideológicas contidas na lógica mercantil, afirmando que os povos caçadores e coletores podem ser, na verdade, protagonistas das primeiras sociedades de afluência: "livres da obsessão de escassez de mercado, as propensões da economia dos caçadores talvez se fundem mais consistentemente na abundância do que nossa economia", pois seu conceito de riqueza e de liberdade não se assenta na necessidade de acumulação infinita de bens; ao contrário, essa idéia de riqueza, assim como a de propriedade, lhe é completamente estranha, estando ausente de seu sistema de referências - fora de sua própria razão. Sem senso de posse e tendo como valor primordial a liberdade dos movimentos, esses povos possuem, não só uma espécie de abundância material - adaptando com prodigalidade seus utensílios à natureza farta em sua volta -, mas uma noção de riqueza peculiar que, com base em suas próprias necessidades, parece integrar, a um só tempo, trabalho e vida. Não se colocando como prisioneiros das pressões materiais, o extenso tempo livre dos caçadores e coletores é dedicado ao cuidado das múltiplas dimensões que compõem sua vida social. Por isso, como observa Sahlins, em vez de concebêlos "como pobres, porque não possuem nada, talvez seja melhor por essa razão, pensar neles como livres". ${ }^{2}$

Assim, mesmo correndo o risco de evocação nostálgica de um passado de abundância e de liberdade - tão

1 Segundo Sahlins (1978), as concepções vulgares de riqueza (ou de afluência) constróem "hipóteses apropriadas particularmente às economias de mercado: as necessidades dos homens são grandes e finitas, enquanto seus meios são limitados, embora possam ser aperfeiçoados: assim a lacuna entre meios e fins pode ser diminuída pela produtividade industrial ao menos para que os produtos ou bens indispensáveis se tornem abundantes" (1978, p. 8).

2 Partindo de premissas opostas à lógica ocidental, Shalins (1978) aproxima a concepção de riqueza dos povos caçadores a uma concepção Zen, "em que as necessidades humanas materiais são finitas e poucas, e os meios técnicos invariáveis mas, no conjunto, adequados. Adaptando-se a estratégia Zen, pode-se usufruir de abundância material sem paralelo - com baixo padrão de vida". 
recorrentes no imaginário ocidental centrado na lógica de inversão -, as formulações de Sahlins fundadas em seus estudos sobre os povos coletores e caçadores adquirem valor e significado diante dos mitos de superioridade da civilização moderna, fundada na lógica de mercado.

Importa marcar, aqui, que, não obstante as prodigiosas formas do homem se produzir no tempo e no espaço, em antítese à sociedade moderna, "os povos da tradição" tendem a ser definidos, na ótica ocidental, por negação ou exclusão, como se, presos às determinações da natureza, sofressem falta de história, estando assim fadados a desaparecer, a permanecer atrás (ou para trás). Ou, no máximo, como se fossem iniciantes - "recitantes apenas do começo."”

Aliás, como se sabe, pode-se dizer em termos sintéticos que, com desdobramentos próprios, dois olhares sobressaem do ocidente: o primeiro, etnocêntrico, que recusa o outro por não ser feito à sua imagem e semelhança: irracionais, pré-lógicos, os povos da tradição, pertencem a uma massa informe de crenças e superstições anacrônicas; o segundo, romântico e nostálgico, o afirma - numa exaltação ao mito do "bom selvagem" - em sua positividade e exotismo, como sendo a expressão do paraíso; o outro, neste caso, representa a virtude, a pureza, a inocência - o estado da plenitude. Entre o céu e o inferno os "povos da tradição" são, pois, ora exaltados, ora negados.

Note-se que ambas as perspectivas, marcadas por um olhar negativo ou positivo, retiram do outro seu caráter de humanidade e as diversas possibilidades históricas e culturais do homem se realizar no tempo e no espaço - independente da instituição do moderno. Ao mesmo tempo, tais visões parecem apartar o outro dos nexos com o universal, destituindo-o da condição que o equaliza como espécie e como ser social, abstraindo-se, daí, a unidade simultânea do ser e sua diversidade.

Convém lembrar que tais imagens atualizadas ou reatualizadas no tempo não se circunscrevem apenas aos povos indígenas concebidos genericamente de maneira compacta e sem fissuras, reduzidos a meras caricaturas. Cravado de preconceitos e estereótipos, esse olhar, positivo ou negativo, projeta-se também aos segmentos não-indígenas inscritos na modernidade, constelando atitudes emocionais poderosas. Refere-se aqui, em particular, aos povos do campo, do mar e da floresta (camponeses, pescadores artesanais, ribeirinhos e seringueiros) que, embora estejam submetidos à modernidade desde sua gênese histórica, conectam-se com a tradição mediante sua forma secular de apropriação da natureza e de seus recursos, de domínio sobre o espaço em suas dimensões materiais e simbólicas. E exatamente por serem vistos como próximos da natureza, com um estilo de vida próprio, dissonante do da sociedade urbano-industrial, são vítimas de toda sorte de estereótipos e discriminações, como se estivessem parados no tempo, insertos no reino natural. Aliás, essa proximidade à natureza ora é negativada, como condição de vida inferior - bichos da selva, bichos do mato; ora é idilicamente positivada.

Debruçando-se sobre as representações do homem do campo e da cidade, presentes no imaginário inglês pós-Revolução Industrial, assim observa Willians (1986, p. 11):

...o campo passou a ser associado a uma forma natural de vida - de paz, inocência e virtude simples: à cidade associou-se a idéia de centro de realizações - de saber, comunicações, luz. Também constelaram-se poderosas associações negativas: a cidade como lugar de barulho, mundianidade; o campo como lugar de atraso, ignorância e limitação.

Embora esse tipo de dualidade remonte já à antiguidade clássica - enquanto expressões de vida fundamentais -, sem dúvida adquirem significação bastante peculiar no imaginário moderno, persistindo, segundo o autor, com sentidos e um poder extraordinário no mundo urbano-industrial do século XX. ${ }^{4}$

Convém salientar que nesses dois olhares, marcados quer pelo romantismo, quer pelo etnocentrismo, os povos da tradição são percebidos como pré-históricos ou semhistória; fazem parte de um tempo mítico, tempo ilusório e estacionário em oposição ao tempo histórico, tempo do progresso, tempo das mudanças, do movimento.

Como dimensões tornadas opostas, em que a segunda domina a primeira, de um lado tem-se a natureza - algo fixo, inerte e homogêneo - como equivalente à tradição; de outro, a história como a expressão do avanço, da modernidade, do fluxo contínuo - a medida de todos os tempos.

Impõe-se sublinhar que a dualidade natureza e cultura aí se faz presente, superpondo-se ou embasando a oposi-

3 Ainda que empregada pelo autor em outro contexto significativo, essa expressão foi tomada de empréstimo de BARTHES, R. Cf. Fragmentos do discurso amoroso. Rio de Janeiro: Francisco Alves, 1989.

4 Cf. WILLIANS, R. O campo e a cidade na história e na literatura. São Paulo: Companhia das Letras, 1990. 
ção tradição e modernidade na sua significação respectiva de atraso e avanço. $\mathrm{O}$ conceito de tradição insere-se na ordem da natureza, como se o primitivo estivesse na condição de atraso por estar próximo à natureza ou a ela submetido. ${ }^{5} \mathrm{E}$ o conceito de desenvolvimento inclui-se na ordem da cultura, representando o avanço tecnológico, as conquistas científicas - o domínio da natureza alcançado pela racionalidade industrial.

Aliás, saliente-se que o desenvolvimento é, nessa perspectiva, tido como sinônimo de industrialização, como um "movimento com uma direção fixa; e, bem entendido, esse próprio movimento pode ser medido sobre um eixo no qual ocupamos, a cada instante, uma abscissa de valor crescente..." (CASTORIADIS, 1987, p. 145).

$$
* * *
$$

Com referência à primeira visão - marcada pela negação -, Pierre Clastres, entre outros antropólogos contemporâneos, chama a atenção sobre o modo através do qual as sociedades tradicionais - particularmente as ditas primitivas - são frequentemente percebidas pela ausência no prisma da civilização ocidental. Sob dois imperativos que regem esse tipo de civilização, a presença do Estado e a necessidade do trabalho, tal autor mostra porque os "primitivos", como seres considerados inferiores, são sempre percebidos pela falta de Estado (expressão máxima da ordem civilizatória) e como indolentes, por terem desprezo ao trabalho - algo que obviamente não se coaduna com o ritmo predominante nas civilizações urbano-industriais contemporâneas. Aliás, como se sabe, o estado de letargia infundido aos selvagens, prende-se ao conceito de trabalho oriundo da lógica mercantil-industrial que se realiza num ritmo mecânico, admitindo o tempo livre somente em oposição direta ao tempo de trabalho.

Nesse sentido, as sociedades indígenas são vistas como estagnadas, sem capacidade tecnológica, produzindo somente no limite da subsistência, aprisionadas que vivem na busca incessante de alimentos. Sabe-se que nenhuma sociedade se estabelece no tempo se não dispõe de um aparato técnico refinado em seu patrimônio cultural; isso significa dizer que cada modesto utensílio produzido por essas sociedades, artesanalmente, constitui na maioria das vezes verdadeiras obras de arte, adaptadas ao meio natural e com capacidade de extrair daí os recursos necessários para a sobrevivência social. Por conseguinte, segundo Clastres (1978), é importante constatar que, de um lado, “os ameríndios em nada se mostram inferiores, muito pelo contrário, no que se refere à arte de selecionar e diferenciar múltiplas variedades de plantas úteis"; de outro lado, como produtores de excedentes não podem ser vistos vivendo no limite da subsistência: a diferença é que suas obras são investidas em formas de troca e reciprocidade, ou seja, de acordo com as necessidades próprias de reprodução da vida material e cultural. Impõe-se, pois, olhar para as sociedades tribais como portadoras de uma lógica própria de conceber a vida, completamente distinta da racionalidade mercantil que rege as sociedades modernas.

Assim, com base no ideário da civilização moderna transposto para as sociedades da tradição - numa mera projeção do presente para o passado -, é que tais sociedades são negadas: pela falta de trabalho, de Estado e de ordem como se fossem ausentes de história, ausentes de cultura. Sob essa ótica, o ocidente utiliza o termo selvagem, reportando-se a um estádio suplantado pela história, ou a uma condição inferior da humanidade em seus primórdios, em oposição à condição de civilizado - quando o "selvagem" traduzido como animal não é expulso para fora da humanidade -, suprimindo-se a diversidade cultural. Nesse sentido, ressalta Clastres (1978): “...Já se percebeu que, quase sempre, as sociedades arcaicas são determinadas de maneira negativa, sob o critério da falta: sociedades sem história, sem escrita..."

Essa obsessão do ocidente pelo etnocentrismo (ou espelhismo) - a medida e o culto de si mesmo -, como sendo sua razão máxima, que só percebe a si próprio como a única possibilidade da humanidade se realizar (forma única, superior e plena) - é, como se sabe, marca dos tempos modernos - do espírito do tempo. Embora, a rigor, o olhar etnocêntrico esteja presente em todos os tempos e lugares - inclusive entre as sociedades ditas primitivas, não sendo portanto uma invenção do ocidente - constitui, sem dúvida, a expressão máxima da ideologia da modernidade em suas distintas versões, produzindo a cisão entre nós $e$ os outros. ${ }^{6}$

\footnotetext{
5 Segundo Balandier (1986) "[...] e até o marxismo, em algumas de suas análises, coloca do lado da natureza, mais do que da história, as formações sociais que 'precedem' a dissolução da continuidade primitiva e a formação das classes. Melhor, ainda, a tradição ali continua a ser vista como uma grande força retardadora que escamoteia e enfraquece os fatores de mudança. Ela não é reconhecida como algo que pode ser reativado, como algo operante e modernizante." (p. 175)

6 Cf. TODOROV, T. Nós e os outros - a reflexão francesa sobre a diversidade humana. Rio de Janeiro: Zahar, 1993. v. 1. Para esse autor, "na acepção dada aqui ao termo 'etnocentrismo', consiste em maneira independente, erigir em valores universais os valores próprios à sociedade a que pertenço. O etnocentrismo (em uma de
} 
Em termos concretos, isso se manifesta não só no confronto entre a civilização ocidental com a primitividade, quanto em relação a toda forma e expressão da diversidade ou da alteridade - com tudo que não lhe é espelho.

Assim, sob a égide da razão prática e instrumental, justifica-se e legitima-se a "missão civilizatória" nas sociedades da tradição, apropriando-se de suas riquezas naturais, materiais e simbólicas, destruindo e/ou desfigurando o outro, transformando-o em não-ser, mero resto ou resquício da história (ou da pré-história) - figura morta.

Como se sabe, isso se presencia em todo o processo de expansionismo europeu, em suas diversas fases, que ao tomar a si como o centro do universo, se move e se reproduz sob a lógica da dominação e destruição, invadindo tempos e espaços distintos - em todos os cantos e recantos do mundo.

$$
* * *
$$

Sob outro prisma, tem observado o antropólogo George Balandier como as chamadas sociedades tradicionais são geralmente percebidas como figuras invertidas, só que desta vez como expressão do positivo, do equilíbrio. Enquanto as sociedades históricas aparecem comandadas pelo ritmo contínuo e incessante das mudanças, aquelas presas aos elos da tradição "abolem a idéia de revolução por estarem fundamentadas sobre a repetição e desnaturadas a partir do momento em que se abrem para a história porque o que elas tiveram que interiorizar permaneceu-lhes estranha e decorreu das dominações sofridas nos últimos séculos”. (BALANDIER, 1976, p. 173)

Problematizando o conceito de história de LéviStrauss, marcado pela oposição entre "as sociedades frias e sociedades quentes", Balandier observa que para esse autor, as sociedades da tradição reproduzem-se pelo ritmo da estabilidade e do consentimento "e escapariam à história porque produzem pouquíssima desordem". Para Balandier, desde o pensamento filosófico clássico até o pensamento de antropólogos modernos, as sociedades da tradição tendem a ser vistas como portadoras de uma ordem fundamental nas relações dos homens entre si e com a natureza, como se elas tivessem tão profundamente confor- madas à ordem estabelecida, à harmonia que, por princípio, recusam a desordem - a mudança, o conflito - e, por isso, são avessas à história.

Em seus estudos contemporâneos, Balandier tem demonstrado como ordem e desordem não são categorias excludentes, mas dialeticamente complementares, configuradoras da vida humana em qualquer tempo e espaço - na tradição e na modernidade. ${ }^{7}$ Em outros termos, o que o autor coloca é que, ao contrário do que se postula no imaginário corrente, a tradição não é sinônimo de ordem e a modernidade de desordem (ou vice-versa); ainda que contrários, ambos os termos fazem parte de um mesmo par de oposição, atuando numa relação de ambivalência e simultaneidade, tanto nas configurações passadas, quanto presentes.

Dessa perspectiva, importa apreender o sentido de historicidade presente em tais sociedades, na forma como ordem e desordem se combinam em múltiplas possibilidades e alinhamentos, considerando que elas não se inscrevem da mesma maneira na história (ou na não-história). ${ }^{8}$

Tal questão coloca em relevo a necessidade de se repensar a noção de tradição empregada, muitas vezes numa acepção fluídica e atemporal, sem se dar conta que o tradicional não se configura como algo imóvel, parado no tempo - mero congelamento do passado -, como se a idéia de movimento ausente nos "povos da tradição" estivesse apenas presente no fluxo dinâmico do ocidente. Nesse sentido é que a tradição aparece como sendo algo estagnado, que expressa somente a continuidade, enquanto a modernidade é vista como sinônimo de mudança, de ruptura.

Assim, por não se inscreverem no ritmo veloz dos tempos modernos que incessantemente parece anunciar a emergência de "novos tempos" (em termos reais e fantasmagóricos), os "povos da tradição" aparecem desprovidos de um sentido de tempo - ou, mais especificamente, de um tempo em movimento -, estando, assim, condenados a serem eternamente os mesmos, eternamente passado. Em tais termos é que a idéia da tradição aparece marcada pela continuidade ininterrupta, pela repetição e estabilidade, não abrindo margem para a variação, enquanto a modernidade se movimenta pelo ritmo contínuo das mudanças, da novidade.

suas versões) é, por assim dizer, a caricatura natural do universalista: este em sua aspiração universal parte de um particular, que se empenha em generalizar, e tal particular deve forçosamente lhe ser familiar, quer dizer, na prática encontra-se apenas em sua cultura" (TODOROV, 1993, p. 21).

7 Cf. BALANDIER, G. Le désordre - Éloge du Mouvement. Paris: Fayard, 1988

8 Para Balandier, mesmo adotando-se, provisoriamente, um ponto de vista anti-historicista, isso significaria afirmar que tais sociedades estariam inseridas de distintas maneiras na não-história. 
É preciso, pois, repensar o conceito de movimento vigente no pensamento moderno, particularmente quando projetado às sociedades da tradição, destituindo-as no sentido de história. Desconsidera-se que, imersas em outros ritmos temporais, essas sociedades se movem em distintas direções, o que requer considerar a dinâmica das tradições em seus próprios termos e, desse modo, apreender como o tempo histórico nelas se irrompe em sua singularidade $;{ }^{9}$ a partir daí, talvez seja possível pensar, inclusive, na quietude do movimento e não somente em sua velocidade.

Para Balandier (1988), além da concepção ocidental não admitir a idéia de movimento e desordem regendo as sociedades da tradição, a elas é negado qualquer possibilidade do novo, qualquer possibilidade para o renascer. Assim, do ponto de vista da razão ocidental, as sociedades da tradição tendem a ser vistas sob dois ângulos: passivas na sua função de conservação da memória coletiva e original; ativas, somente enquanto representação do que foi - do que já existiu. Por isso, elas se inscrevem no presente apenas como prolongamento do passado, ou como mera metáfora desse momento que já passou. Sua existência só se realiza, quando a tradição é identificada com uma idade inicial, originária da humanidade, com sua fundação. É nesses termos que o "outro" aparece positivado, como pertencente ao início do estágio evolutivo da humanidade ou como portador de uma vida harmônica - desprovida de desordens.

Convém observar que, para o autor em foco, essas visões se presenciam, muitas vezes, no próprio interior do pensamento antropológico, cujo olhar tem sido voltado para as chamadas sociedades da tradição: inicialmente, preso às amarras da ideologia do progresso, "os primitivos" são vistos, no bojo do pensamento evolucionista, como mera reminiscência atemporal do passado - racionalidade morta. Quando eles não são percebidos como sobrevivência de um tempo remoto - na tentativa de apreendê-los em seus próprios termos -, acabam, muitas vezes, sendo apartados da história, vistos apenas em seu perpétuo presente etnográfico.

Assim, sem negar o desafio que a antropologia traz para o pensamento ocidental de se compreender as alteridades, o que se quer realçar, aqui, é que a noção de tempo que perpassa seu olhar sobre a tradição aparece muitas vezes prisioneira das teias vigentes na ordem tem- poral do ocidente. Essas considerações, aqui postas provisoriamente, requerem, sem dúvida, um debruçar mais detido sobre os diferentes olhares antropológicos acerca da tradição, o que escapa dos limites do presente estudo.

Balandier há de pensá-las como repetidoras de suas formas puras e originais, ausentes de quaisquer dinamismos, sejam internos, sejam externos. Presas aos "mandamentos do passado", em termos gerais e, sumariamente, tal tipo de sociedade tende ser assim configurada:

...trata-se de uma sociedade conformada aos modelos implicados pela carta mítica (as 'tradições')..., em observância à concepção primeva e mantida da ordem do mundo e da ordem dos homens (...); de uma sociedade do conformismo e do consensus que não dá lugar (ou pouco) à divergência de opiniões e, portanto, à contestação (...); de uma sociedade repetitiva, que reproduz suas estruturas de geração em geração e sem variações significativas (...), de uma sociedade situada fora da história ou à margem dela [...] (BALANDIER, 1976, p. 215).

Segundo Balandier (1976), os problemas presentes na relação etnologia e história ainda requerem uma reflexão sistemática e completa. Entretanto, sem pretensão de recobrir o pensamento antropológico como um todo, o autor cita alguns pontos de vista dinamistas que se sucederam no âmbito da antropologia inglesa, ainda que em gérmen.

Para ele, Evans-Prichard é um dos antropólogos “que recorre explicitamente a modelos tomados da história e das disciplinas clássicas [e] chega a constatar que todas as sociedades são o produto de um contínuo processar, de uma sucessão de acontecimentos específicos e que o passado atualiza-se sempre no presente". Outros autores são citados por se valerem da perspectiva histórica em suas investigações: é o caso, por exemplo, de Leach, que sugere que as sociedades tradicionais não sejam vistas como sistemas fechados e perfeitamente equilibrados, fora do tempo: seu estudo entre os Kachin da Birmânia revela a existência de uma espécie de história pendular, que "oscila entre formas mais igualitárias e formas não igualitárias da vida social". Nessa visão histórica incluem-se também os trabalhos de 
Max Glukman que "consideram, à base de dados de observação direta, o papel do conflito e a natureza da inércia social; tratam eles da dialética da ordem e da rebelião, da permanência e da mudança". (BALANDIER, 1976, p. 178). ${ }^{10}$

Além de Balandier, outros autores contemporâneos - anteriormente citados -, vêm abordando as conexões (e tensões) entre Etnologia e História, o que revela que a questão da historicidade dos povos tradicionais vem suscitando, há muito tempo, reflexão e debate: "povos sem história", "história estacionária versus história cumulativa", "história fria versus história quente", são algumas das formulações que, além de providas de um conteúdo etnocêntrico, expressam talvez a profunda incapacidade da antropologia considerar a história de seus "objetos de estudo" como algo mais que mera história reflexa.

\section{REFERÊNCIAS}

BALANDIER, G. Antropologia política. São Paulo: Universidade de São Paulo, 1969.

Paulo, 1976.

Antropo-lógicas. São Paulo: Universidade de São 1988.

Le desordre Éloge du Mouvement. Paris: Fayard,

O contorno - poder e modernidade. Rio de Janeiro:

Bertrand Brasil, 1997.

CASTORIADIS, C. As encruzilhadas do labirinto. Rio de Janeiro: Paz e Terra, 1987. n. 1-2.

CLASTRES, P. A sociedade contra o Estado. Rio de Janeiro: F. Alves, 1978.

CUNHA, L. H. O. Tradição e modernidade: imagens, tempos e movimentos. São Paulo: PUC, 1996. Mimeog.

EVANS-PRITCHARD, E. E. Os Nuer. São Paulo: Perspectiva, 1978.
A antropologia se define como uma ciência que busca o entendimento do outro nas manifestações mais gerais e mais específicas da cultura humana: como entender e aceitar então que se conceba esse outro como entidade essencialmente inerte, já que nessa concepção a força dinâmica é sempre externa, gerada unicamente no mundo ocidental?

Enquanto distante e estranho, o outro, vive e atua apenas na medida em que seu movimento incide no universo do conquistador e deixa de ser pensado em sua historicidade, como produto da conjunção entre as forças internas e externas, as quais atuam de modo próprio no encontro e/ou no confronto entre tradição e modernidade. ${ }^{11}$
GODELIER, M. Historicidade e o pensamento primitivo. In: CARVAlHO, E. A. Godelier. São Paulo: Ática, 1981.

LEACH, E. Repensando a Antropologia. São Paulo: Perspectiva, 1974.

WILLIANS, R. O campo e a cidade na história da literatura. São Paulo: Cia. das Letras, 1990.

PIRES, M. L. Resenha sobre Europe and People Without History, de Eric Wolf. [S.1.], 1990. Mimeog.

SAHLINS, M. A primeira sociedade da afluência. In: CARVALHO, E. Antropologia econômica. São Paulo: Ciências Humanas, 1990.

TODOROV, T. Nós e os outros - a reflexão francesa sobre a diversidade humana. Rio de Janeiro: Zahar, 1993.

10 Para uma visão contemporânea do entrelaçamento entre etnologia e história ver BALANDIER, G. nas obras citadas; SHALINS, M. As Ilhas da História; WOLF, E. Europe and the people without History. [S.1.:s.n.], 1982; GODELIER, M. Mito e História: reflexões sobre os fundamentos do pensamento selvagem. [S.1.:s.n., 19-] 11 Essas considerações baseiam-se em PIRES, M. L. Resenha sobre Europe and People Without History, de Eric Wolf. [S.1.], 1990. Mimeog. 